\title{
Projecting Global and Regional Forest Area under the Shared Socioeconomic Pathways Using an Updated Environmental Kuznets Curve Model
}

\author{
Prakash Nepal ${ }^{1, *}$, Jaana Korhonen ${ }^{2,3}$, Jeffrey P. Prestemon ${ }^{4}$ and Frederick W. Cubbage ${ }^{5}$ \\ 1 Department of Forestry and Environmental Resources, North Carolina State University, \\ 3041 E. Cornwallis Rd., Research Triangle Park, NC 27709, USA \\ 2 University of Helsinki, Viikki Campus, Latokartanonkaari 7, P.O. Box 27, 00014 Helsinki, Finland; \\ jaana.e.korhonen@helsinki.fi \\ 3 Helsinki Institute for Sustainability Science (HELSUS), University of Helsinki, 00014 Helsinki, Finland \\ 4 USDA Forest Service, Southern Research Station, Forestry Sciences Laboratory, 3041 E. Cornwallis Road, \\ Research Triangle Park, NC 27709, USA; jeff.prestemon@usda.gov \\ 5 Department of Forestry and Environmental Resources, North Carolina State University, 2820 Faucette Dr., \\ Campus Box 8001, Raleigh, NC 27695, USA; cubbage@ncsu.edu \\ * Correspondence: pnepal@ncsu.edu or prakash.nepal@usda.gov; Tel.: +1-919-549-4067
}

Received: 2 April 2019; Accepted: 27 April 2019; Published: 30 April 2019

\begin{abstract}
Forest resources are critical to environmental, economic, and social development, and there is substantial interest in understanding how global forest area will evolve in the future. Using an Environmental Kuznets Curve (EKC) model of total forest area that we updated using more recent data sets, we projected forest area through 2100 in 168 countries using variables including income, rural population density, and the size of the labor force under different world visions drawn from alternative Intergovernmental Panel on Climate Change socioeconomic pathways (SSPs). Results provided support for the existence of an EKC for total forest area, with rural population density negatively affecting forest area and labor force size positively affecting forest area. The projections showed modest and continuous increases in global forest area in all the SSPs, but varying trends for major world regions, which is consistent with the projected trends from the explanatory variables in each country. Aggregate global forest area is projected to increase by $7 \%$ as of 2100 relative to 2015 levels in SSP3, which predicts a future with the lowest rate of economic growth, and by $36 \%$ in SSP5, which is a future with the highest rate of economic growth and greater economic equality across countries. The results show how projections driven only by income produce biased results compared to the projections made with an EKC that includes rural population density and labor force variables.
\end{abstract}

Keywords: Environmental Kuznets Curve; shared socioeconomic pathways; global forest area projections; forest sector modeling; forest sector policy

\section{Introduction}

Numerous scientific studies over decades have addressed reasons behind the spatial and temporal changes in environmental variables (e.g., level of pollution, rate of deforestation, etc.). The primary goals of those studies have been to help policy makers better understand the effects of policy changes and understand prospective future changes, given changes in societies. Several of these studies based their empirical approaches on the Environmental Kuznets Curve (EKC) hypothesis [1], which describes an inverted U-shaped relationship between changes in an environmental variable (e.g., pollution, deforestation) and per capita income (Y/N) [2-4]. 
Applied to forest resources, the EKC hypothesis describes a long-term relationship between deforestation (or forest area) and Y/N [5-8]. The EKC implies that the loss of forest area increases with rising $\mathrm{Y} / \mathrm{N}$ during the earlier stages of economic growth, reaches a peak, and then diminishes with further increases in $\mathrm{Y} / \mathrm{N}$. The decrease and eventual reversal in forest loss with higher $\mathrm{Y} / \mathrm{N}$ is posited to derive from increased awareness and concern for (desire for) environmental conservation and protections, and is enabled through the enactment of environmental regulations and implementation of policies and programs promoting forest protections and expansion, as well as increasing investments in the forest sector [4].

The existence of a parabolic relationship between deforestation (or forest area) and $\mathrm{Y} / \mathrm{N}$ is typically tested empirically by hypothesizing a quadratic form equation. For the EKC, forest loss is related to $\mathrm{Y} / \mathrm{N}$ and $(\mathrm{Y} / \mathrm{N})^{2}$, which have expected positive and negative coefficients, respectively. Likewise, relating forest area to these same terms should generate a negative coefficient for $\mathrm{Y} / \mathrm{N}$ and a positive coefficient for $(\mathrm{Y} / \mathrm{N})^{2}[8,9]$. Empirical study of these relationships to $\mathrm{Y} / \mathrm{N}$ often includes attention to additional (control) variables that further explain changes in deforestation or forest area. Control variables could include macroeconomic, institutional, and societal variables which, if found to be significant, provide additional insights into the proximate drivers of observed changes in forests area over time and across countries or regions, potentially informing policy.

Econometric analyses of the EKC or forest area change, viewed in toto, provide conflicting evidence on the existence of their relationships to $\mathrm{Y} / \mathrm{N}$ [3,5-15]. While a systematic assessment of the evidence in support of the EKC is still lacking, the existing mixed support for the hypothesis may result from diversity in empirical specifications such as a variety of control variables, different sets of countries, time spans, types of data, and varied statistical methods applied.

Among the first empirical tests of the EKC for deforestation was by Shafik and Bandhopadhya [3], who found no empirical support for the existence of either linear, quadratic, or cubic relationships between deforestation (both annual and total) and $\mathrm{Y} / \mathrm{N}$ using data from 1961-1986. In contrast, Panayotou [5], who modeled deforestation as a quadratic function of $\mathrm{Y} / \mathrm{N}$ and population density using cross-sectional data on deforestation for 47 developing countries and 68 developing and developed countries combined, found support for the EKC for both country groups. Their results also suggested that deforestation reached a peak rate at a Y/N of $\$ 823$ for developed countries and at $\$ 1200$ for all the countries combined. Similarly, Cropper and Griffiths [6], when evaluating both pooled cross-sectional and time-series data for countries in Latin America, Africa, and Asia between 1961-1986, found evidence supporting an inverted U-shaped relationship between the rate of deforestation and $\mathrm{Y} / \mathrm{N}$ for Latin American and African countries, but no such evidence for Asia.

Bhattarai and Hammig [7], adding political, institutional, and macroeconomic policy factors as control variables, estimated a cubic model of deforestation by Africa, Asia, and Latin America using data from 66 countries, 1972-1991.They found strong statistical support for the existence of an EKC relationship between $\mathrm{Y} / \mathrm{N}$ and deforestation for all three continents. They also found evidence for the importance of population and institutional factors, with mixed evidence on the significance of macroeconomic policy and technology factors across those three continents. Similarly, Culas [13] examined Africa, Asia, Latin America, and the world, using data for 14 countries, 1972-1994, finding evidence for an EKC for deforestation only for Latin America.

Turner et al. [14] estimated an EKC model of country level forest area change as a function of scale, technique, and composition effects represented by $\mathrm{Y} / \mathrm{N}$, rural population density, labor force, capital, and a country's openness to trade. Their results provided strong support for the EKC and also for the importance of rural population density and labor per unit of forest area in explaining annual forest area change across countries. Two relatively recent studies also provided evidence for the existence of an EKC related to forest area changes. Cuaresma et al. [9] found an empirical support for the existence of an EKC for forest cover, which was indicated by a statistically significant negative coefficient on $\mathrm{Y} / \mathrm{N}$ and a positive coefficient on $(\mathrm{Y} / \mathrm{N})^{2}$. In contrast, Joshi and Beck [8] found evidence for the existence of a U-shaped EKC relationship between total forest area and $\mathrm{Y} / \mathrm{N}$ only for Africa, an $\mathrm{N}$-shaped curve 
for countries in the Organization for Economic Co-operation and Development (OECD), no curve for Asia, and an inverse U-shaped curve for Latin America. Finally, we note that [11,12,15], among others, found no empirical support for the existence of an EKC for deforestation. As can be discerned from the discussion above, the existence of an EKC for deforestation or forest area is still debated, suggesting a need for more empirical research as new and improved data become available.

This study contributes to the current EKC literature by providing an updated estimate of the EKC model of forest area using sets of panel data capturing historical and the most recent socioeconomic trends. The underlying relationships between forest area and $\mathrm{Y} / \mathrm{N}$ might have altered due to rapid global population growth and urbanization in many of the countries historically most beset by forest loss, ongoing technology change, the expansion of planted forests (particularly in Latin America), and global shifts in comparative advantage in the forest sector. Furthermore, given a recent revision to the definition of forest area by the Food and Agriculture Organization (FAO) [16], there is need to revalidate the previous studies assessing the forest area change based on the FAO data. For example, forests that regenerate following harvest are now counted as forest, according to the new definition [16], which in many cases were either not classified as forest or inconsistently classified as forests in earlier data compilations.

While this study presents new analyses of the EKC in the context of macroeconomic and data definitional shifts, it also offers a vision of the prospective future of forests globally. Our projections of forest area by country (presented at aggregate regional and global levels) are driven not only by the projected $\mathrm{Y} / \mathrm{N}$ and its squared value, but also by projected rural population density and labor per unit forest area, which is an advance beyond past studies, which either provided only statistical inferences or offered projections of forest area driven only by projected $\mathrm{Y} / \mathrm{N}$ and $(\mathrm{Y} / \mathrm{N})^{2}$ e.g., [14,17]. Finally, by evaluating the projected forest area trends globally and across major world regions, under alternative future scenarios of economic and demographic changes, this study gauges the usefulness of the estimated EKC model in providing a plausible projection of forest area that will be needed in future studies and or policy simulations employed in global forest sector models.

\section{Materials and Methods}

While there were numerous studies and model specifications to choose from, which we could update with more recent data sets, we chose to revisit Turner et al.'s [14] study for two important reasons. First, by including capital and labor use per unit of forest area, their model captures the effect of investment in the forest sector, which is further affected by timber prices, harvest quantities, and the overall profitability of the sector. Given that several of these variables have shifted substantially in the last decade, adoption of their model will allow us to understand how economic changes may have affected empirical relationships. Second, their EKC specification offers an opportunity to capture the effects of technique, scale, and composition on forest area, based on methods suggested by Antweiler et al. [18] and Cole and Elliot [19]. While the scale effect captures the declining forest area at the initial stage of economic development, resulting from rising consumption (and production) of forest products with increased incomes, the technique effect captures the economic development phases, where demand for the conservation and expansion of forests are greater as $\mathrm{Y} / \mathrm{N}$ further increases [14]. The composition effect mimics the economic situation where the mix of products that a country produces may change as income rises [14]. While other past studies might well have captured the technique and scale effects in explaining forest area, they did not include the composition effects that are important in modeling forest area-related EKC. Finally, the inclusion of trade intensity (openness to trade), which interacted with other variables in their model, allows us to capture the effects of the comparative advantage of a country in producing and trading a product (and hence the effect on total forest area). 
Following Turner et al. [14], the total forest area in the EKC model estimated in this study is represented in Equation (1):

$$
\begin{aligned}
A_{i t}=\beta_{0}+\beta_{1}\left(\frac{Y}{N}\right)_{i t} & +\beta_{2}\left(\frac{Y}{N}\right)_{i t}^{2}+\beta_{3} U_{i t} \\
& +\beta_{4}\left(\frac{L}{A}\right)_{i t}+\beta_{5}\left(\frac{K}{A}\right)_{i t}+\beta_{6}\left(\frac{L}{A}\right)_{i t}\left(\frac{K}{A}\right)_{i t}+\beta_{7} \varnothing_{i t} I_{i t}+\varepsilon_{i t}
\end{aligned}
$$

where,

$A_{i t}=$ total forest area (ha) in country $i$ at time $t$. Thus, any changes in the total forest area represent the net of changes in deforestation and/or afforestation from time $t-1$ to time $t$

$\beta=$ constant $\left(\beta_{0}\right)$ and coefficients associated with the independent variables $\left(\beta_{1}\right.$ to $\left.\beta_{7}\right)$

$\left(\frac{Y}{N}\right)_{i t}=$ per capita gross domestic product (GDP, 2010 constant USD) in country $\mathrm{i}$ at time $\mathrm{t}$

$R_{i t}=$ rural population density (person $\mathrm{ha}^{-1}$ ) in country $\mathrm{i}$ at time $\mathrm{t}$, a proxy for scale of forest use

$\left(\frac{L}{A}\right)_{i t}=$ ratio of labor to forest area in country $\mathrm{i}$ at time $\mathrm{t}$

$\left(\frac{K}{A}\right)_{i t}=$ ratio of capital to forest area in country $\mathrm{i}$ at time $\mathrm{t}$

$I_{i t}=$ ratio of the value of exports plus imports to GDP (trade intensity) in country $\mathrm{i}$ at time $\mathrm{t}$

$\varnothing_{i t} \cong \varnothing_{0}+\varnothing_{1}\left(\frac{Y}{N}\right)_{i t}+\varnothing_{2}\left(\frac{L}{A}\right)_{i t}+\varnothing_{3}\left(\frac{K}{A}\right)_{i t}+\varnothing_{4}\left(\frac{L}{A}\right)_{i t}\left(\frac{K}{A}\right)_{i t}$, suggesting that the marginal effect of trade intensity on total forest area depends on the levels of other variables

$\varepsilon_{i t}=$ random error for country $\mathrm{i}$ at time $\mathrm{t}$

The dependent variable in Turner et al.'s [14] model was the "annual percentage change in forest area", as opposed to the "total forest area" used in this study. We chose total forest area as our dependent variable because our interest here was to model total forest area, which is determined by net changes in both deforestation and afforestation. Since the dependent variable is "total forest area", the sign of $\mathrm{Y} / \mathrm{N}$, according to the EKC hypothesis, should be negative, while the sign of $(\mathrm{Y} / \mathrm{N})^{2}$ should be positive. The sign for the rural population density $(\mathrm{R})$ should be negative, since the relationship between total forest area and rural population density is expected to be negative. It is expected that countries with higher labor and capital per unit of forest area (L/A, and K/A, respectively) require less forest input to produce a unit forest output (hence less timber harvest and more forest), and therefore their signs should be positive. Since trade intensity (I) is the measure of a country's comparative advantage in producing and trading a forest product, it should have a positive effect on total forest area.

Data used in estimating the EKC model (Equation (1)) comprised 116 countries at five different time points $(1990,2000,2005,2010$, and 2015), giving a total of 585 observations. The total forest area data came from the Food and Agricultural Organization's Global Forest Resource Assessment Report [20]. GDP, population, and labor force data were obtained from the World Bank [21]. Finally, data on capital stock and trade intensity were obtained from the Penn World Table database [22]. Table 1 provides the description of all the variables used in estimating Equation (1), including units of measure, data sources, and summary statistics.

We estimated three different panel data model specifications, including the pooled ordinary least squares (OLS), fixed effects (FE), and random effects (RE) models, each of which was estimated using a logarithmic transformation of all the continuous variables, so estimated coefficients represent elasticities, which were further evaluated to identify the statistically most superior model based on a pooling test and a Hausman test. The models were estimated using Stata 14/IC using normal, robust, and (country) clustered standard errors to control for the effects of heteroskedasticity in the model. 
Table 1. Description of variables used in estimating the Environmental Kuznets Curve (EKC) model of global total forest area and their summary statistics. The total number of countries was 117, giving 585 total observations, with Africa (45), Asia (26), Europe (21), North America (14), South America (10) and Oceania (2). Data time periods were 1990, 2000, 2005, 2010, and 2015. FAO: the Food and Agriculture Organization, GDP: gross domestic product.

\begin{tabular}{|c|c|c|c|c|c|}
\hline Variable & Description & Unit & Data Source & Mean & SD \\
\hline$A$ & Total forest area & Hectare (ha) & FAO [20] & $19,774,898$ & $59,211,845$ \\
\hline$Y / N$ & GDP per capita ${ }^{1}$ & 2010 constant US \$ & World Bank [21] & 11,245 & 17,374 \\
\hline$R$ & $\begin{array}{l}\text { Population per unit } \\
\text { forest area }{ }^{2}\end{array}$ & Person ha ${ }^{-1}$ & $\begin{array}{l}\text { World Bank [21] } \\
\text { FAO [20] }\end{array}$ & 35,190 & 175,102 \\
\hline$L / A$ & $\begin{array}{l}\text { Labor per unit } \\
\text { forest area }{ }^{3}\end{array}$ & Person ha ${ }^{-1}$ & $\begin{array}{l}\text { World Bank [21] } \\
\text { FAO [20] }\end{array}$ & 14 & 72 \\
\hline$K / A$ & $\begin{array}{l}\text { Capital per unit } \\
\text { forest area }{ }^{3}\end{array}$ & $\begin{array}{l}2010 \text { constant US \$ } \\
\text { ha }^{-1}\end{array}$ & $\begin{array}{c}\text { Feenstra et al. [22] } \\
\text { FAO [20] }\end{array}$ & $1,899,282$ & $15,024,722$ \\
\hline$I$ & $\begin{array}{c}\text { Trade identity } \\
\text { (openness to trade) }\end{array}$ & $\begin{array}{l}\text { Ratio of export and } \\
\text { import value to } \\
\text { GDP }\end{array}$ & Feenstra et al. [22] & 0.54 & 0.46 \\
\hline
\end{tabular}

Note: ${ }^{1}$ captures technique effect, ${ }^{2}$ proxy for rural population density capturing the scale of forest use, ${ }^{3}$ captures composition effect.

Following estimation of the three models, the statistically superior model was then used to project the total forest area in each individual country through 2100 under various scenarios of socioeconomic changes represented in five different shared socioeconomic pathways (SSPs), which were developed in conjunction with the most recent global climate modeling of the International Panel on Climate Change (IPCC). These SSPs further describe different socioeconomic, technological, environmental, and policy futures of the world, with varying degree of challenges for climate change mitigation and adaptation [23]. For instance, the SSP1 and SSP5 scenarios represent the wealthiest and more equal world visions, with SSP1 describing a more sustainable world vision compared to SSP5, which is assumed to have a high dependence on fossil fuels for energy. SSP2 could be referred to as a "business-as-usual" world, in which the most recent trends in population and economic growth, among other factors, would be expected to continue. In contrast, SSP3 and SSP4 represent global futures in which the world overall is poorer; the former indicates lower economic growth across most countries, and the latter indicates faster economic growth generally only with wealthier countries.

Projections of total forest area were made for 168 countries under each SSP for which the projected data on the explanatory variables were available. The projections were made using the projected income per capita $(\mathrm{Y} / \mathrm{N}),(\mathrm{Y} / \mathrm{N})^{2}$, rural population density $(\mathrm{R})$, and labor per unit forest area $(\mathrm{L} / \mathrm{A})$. We assumed that the values for non-included variables were constant throughout the projection period. Data on the future GDP $(\mathrm{Y})$ and population $(\mathrm{N})$ for each country in each SSP were obtained from the International Institute for Applied Systems Analysis [24]. To obtain the projections for L/A data, we assumed that the L/A value in 2015 would grow at the same rate as the projected population in each SPP. Projected values for R for each country in each SSP were estimated using the projected data on total population [24], projected share of rural population [25], and the 2015 total land area values for each country [21]. Future proportions of rural land area in each SSP were assumed to correspond to the proportion of the rural population projected for each SSP by Jiang and O'Neill [25]. Thus, the estimated projections for $\mathrm{R}$ were obtained by dividing the rural population by rural land area (obtained by multiplying the total land area in 2015 with projected proportion of rural population). Figures S1-S3 in the Supplementary Materials summarize the projected average data on $\mathrm{Y} / \mathrm{N}, \mathrm{R}$, and L/A for major world regions. The projected world regional trends on these variables generally mimic the respective trends for individual countries within each region, which largely determined the projected trajectory of the total forest area across SSPs. 


\section{Results}

\subsection{Updated EKC Model of Total Forest Area}

The pooling test rejected the null hypothesis, supporting the premise that there is significant variation in socioeconomic and biophysical factors that may affect changes in forest area in a country or a region. The Hausman test indicated a better fit for the FE model over the RE model, whose estimated parameters we used in projecting future total forest area.

Table 2 summarizes the expected signs and the estimated coefficients of the explanatory variables, standard errors, and their statistical significances for the superior FE model (the pooled OLS and the RE model results are available by request). All the estimated coefficients (elasticities, given the logarithmic transformation of the data) had signs in the expected direction, although the signs for the interaction terms were unknown a priori. A statistically significant and negative coefficient for $\mathrm{Y} / \mathrm{N}$ and a positive coefficient for $(\mathrm{Y} / \mathrm{N})^{2}$ confirm the existence of a U-shaped relationship between total forest area and income per capita (Table 2). However, the estimated partial effects of R and L/A are statistically significant and substantially larger than the estimated partial effects of $\mathrm{Y} / \mathrm{N}$ and $(\mathrm{Y} / \mathrm{N})^{2}$. The larger magnitude effects suggest that $\mathrm{R}$ and L/A are two important variables affecting future forest area, and that projections of forest area without including these variables might be misleading. Although the sign on the coefficient for K/A was negative, contrary to its expected sign, it was not statistically significant. However, the interaction term, L/A*K/A, was statistically significant, suggesting that increasing K/A would only help to increase total forest area if there were increasing L/A values. The effect of trade intensity (I) in explaining total forest area was also not statistically significant, although it had the expected positive sign. However, the interaction terms of I with $\mathrm{Y} / \mathrm{N}$ and $\mathrm{K} / \mathrm{A}$, respectively, were statistically significant and positive, suggesting that increasing trade openness is aligned with increased forest area only with increasing $\mathrm{Y} / \mathrm{N}$ or increasing K/A. Finally, the interaction term I* L/A*K/A was also not statistically significant.

Table 2. Expected signs, estimated coefficients, standard errors, and significance levels of the Environmental Kuznets Curve (EKC) model of global total forest area.

\begin{tabular}{|c|c|c|c|c|}
\hline \multirow{2}{*}{$\begin{array}{c}\text { Variables } \\
(Y / N)_{i t}\end{array}$} & \multirow{2}{*}{$\begin{array}{c}\text { Expected Sign } \\
-\end{array}$} & \multicolumn{3}{|c|}{ Estimated Fixed Effect Model $^{1}$} \\
\hline & & -0.1600 & $(0.1000)$ & * \\
\hline$(Y / N)_{i t}^{2}$ & + & 0.0147 & $(0.0100)$ & $* *$ \\
\hline$R_{i t}$ & - & -0.7007 & $(0.0070)$ & $* * *$ \\
\hline$(L / A)_{i t}$ & + & 0.4187 & $(0.0070)$ & $* * *$ \\
\hline$(K / A)_{i t}$ & + & -0.0100 & $(0.0100)$ & \\
\hline$I_{i t}$ & + & 0.0197 & $(0.0500)$ & \\
\hline$(L / A)_{i t}^{*}(K / A)_{i t}$ & unknown & 0.0003 & $(0.0001)$ & $* * *$ \\
\hline$I_{i t}^{*}(Y / N)_{i t}$ & unknown & 0.0238 & $(0.0100)$ & ** \\
\hline$I_{i t}^{*}(L / A)_{i t}$ & unknown & 0.0295 & $(0.0200)$ & \\
\hline$I_{i t}^{*}(K / A)_{i t}$ & unknown & -0.0200 & $(0.0100)$ & ** \\
\hline$I_{i t}{ }^{*}(L / A)_{i t} *(K / A)_{i t}$ & unknown & 0.0025 & $(0.0001)$ & \\
\hline Intercept & unknown & 25.6900 & $(1.0700)$ & $* * *$ \\
\hline $\mathrm{R}^{2}$ (adjusted) & & 0.3800 & & \\
\hline Pooling test & & 117.24 & $* * *$ & \\
\hline Hausman test & & 24.20 & $* *$ & \\
\hline
\end{tabular}

Note: numbers in parentheses are standard errors; ${ }^{* * *}$ statistically significant at $1 \%,{ }^{* *}$ at $5 \%$, and ${ }^{*}$ at $10 \% ;{ }^{1}$ specified model was a log-log model, and therefore the estimated coefficients are also estimates of elasticities.

\subsection{Projected Global Forest Area}

Next, we projected the total forest area from 2015 to 2100 for 168 countries under three contrasting futures of economic and demographic changes projected in SSP2, SSP3, and SSP5 (we also obtained projections for SSP1 and SSP4, but did not report the results here, because the SSP1 results were close to those of SSP5, and the SSP4 results were close to those of SSP2. The projected results for SSP1 and 
SSP4 are available upon request), using the updated EKC model coefficients (Table 2) and the projected data for four explanatory variables $\left(\mathrm{Y} / \mathrm{N},(\mathrm{Y} / \mathrm{N})^{2}, \mathrm{~L} / \mathrm{A}\right.$, and $\left.\mathrm{R}\right)$. The projections showed that the global (168 countries for which projected data on explanatory variables were available. Projected forest area for individual country are available upon request) total forest area would increase in all SSPs, albeit slowly at the beginning (roughly through 2035), then increasing at a higher rate thereafter (Figure 1). Based on our estimated parameters of the EKC model (Table 2), the increase in Y/N and L/A contribute to higher forest area, whereas an increase in $\mathrm{R}$ had the opposite effect. Accordingly, SSP5, with the highest projected Y/N (Figure S1a-f) and the lowest projected R (Figure S2a-f) in most of the countries, is projected to show the largest increase in global forest area (by 36\% by 2100, relative to 2015). The low rate of projected growth in L/A (Figure S3a-f) for SSP5 helped to dampen the projected overall increase in total forest area. In contrast, SSP3, with the lowest $\mathrm{Y} / \mathrm{N}$ increase and the highest $\mathrm{R}$ growth for the majority of the countries, generated the lowest global forest area increase (by $7 \%$ by 2100 , relative to 2015). With intermediate growth in explanatory variables in all countries, the SSP2, representing a world future evolving along at current trends, generated a 17\% increase in total forest area by 2100 , relative to 2015 .

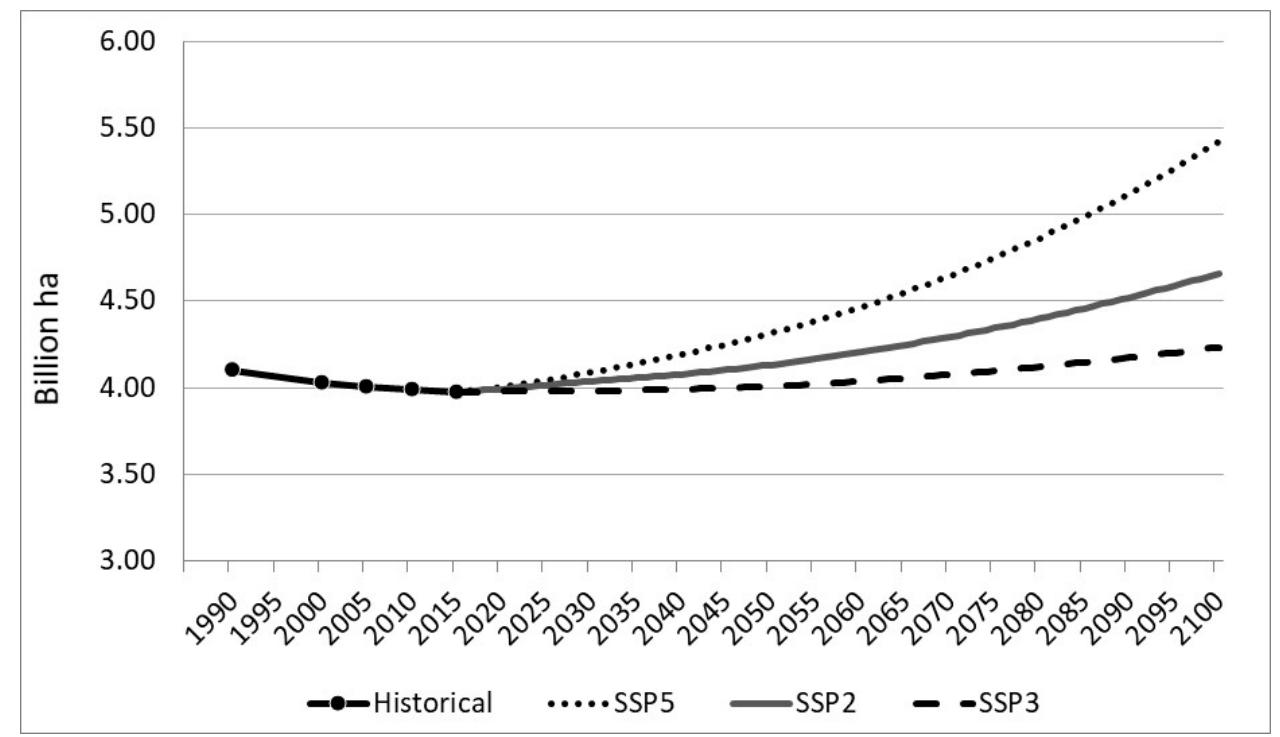

Figure 1. Projected global total forest area (billion ha) under different shared socioeconomic pathways (SSPs), 2015-2100. Projected explanatory variables driving total forest area projection include per capita income, its squared term, labor per unit forest area, and rural population density. The results represent the sum of projections for 168 countries including 48 countries in Africa, 46 in Asia, 36 in Europe, 17 in North America, nine in Oceania, and 12 in South America.

While the projected global forest area trends across SSPs were similar for the majority of countries and regions (Table S1), the global results masked important differences in future forest area in some countries and regions, due in part to divergent $\mathrm{R}$ and L/A trends. For example, Africa (Figure 2a) demonstrated a continuous decline in forest area in SSP3 (by 21\% less in 2100, relative to 2015), which was a result stemming from slow economic growth (Figure S1a) and a rapid increase in R (Figure S2a), although somewhat countered by L/A growth in this scenario (Figure 3a). Projected high levels of economic growth coupled with very low R in SSP5 resulted in a 30\% increase in forest area in Africa, with SSP2 showing an increase of only $1 \%$ by 2100.

The projected forest area trends in Asia (Figure 2b) and Europe (Figure 2c) were similar but relatively higher than the projected global forest area trends (Figure 1). For instance, while Asia showed forest area increases of $64 \%, 34 \%$, and 14\% in SSP5, SSP2, and SSP3, respectively (Figure 2b), Europe showed corresponding increases of 40\%, 23\%, and 16\% by 2100, relative to 2015 (Figure 2c), which were in agreement with the $\mathrm{Y} / \mathrm{N}, \mathrm{R}$, and L/A values projected for Asia and Europe, respectively. 
For instance, projected high and increasing $\mathrm{Y} / \mathrm{N}$ (Figure S1b) and labor per unit forest area (Figure S3b) values coupled with lower and declining $\mathrm{R}$ (Figure S2b) values in Asia contributed to higher forest area in SSP5. Similarly, larger and increasing projected Y/N and L/A trends for Europe (Figures S1c and S3c, respectively) contributed to increased forest area in SSP5, despite larger projected $\mathrm{R}$ values (Figure S2c). South America (Figure 2f) mimicked the projected forest area trends of Asia for SSP5 and SSP2, with projected increases of $53 \%$ and $24 \%$ by 2100 , respectively, relative to 2015 . However, SSP3, which had a relatively high projected $\mathrm{R}$ value in South America (Figure S2f), generated barely increasing forest area (only $2 \%$ increase by 2100 , relative to 2015 ).

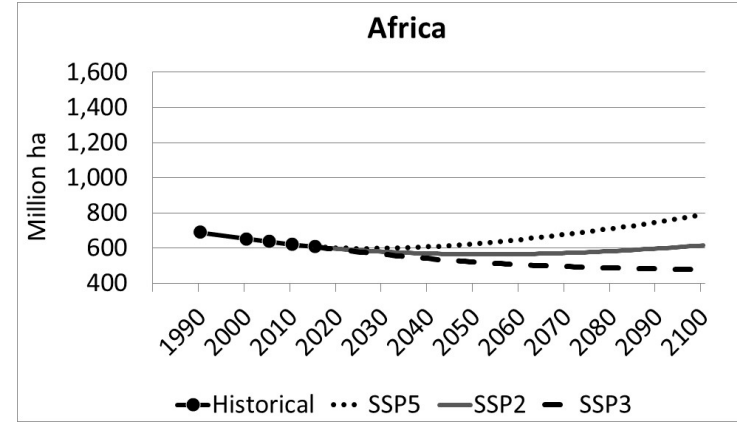

(a)

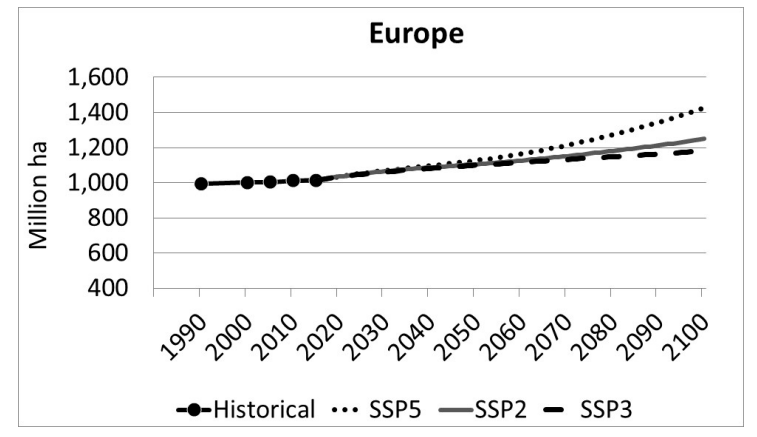

(c)

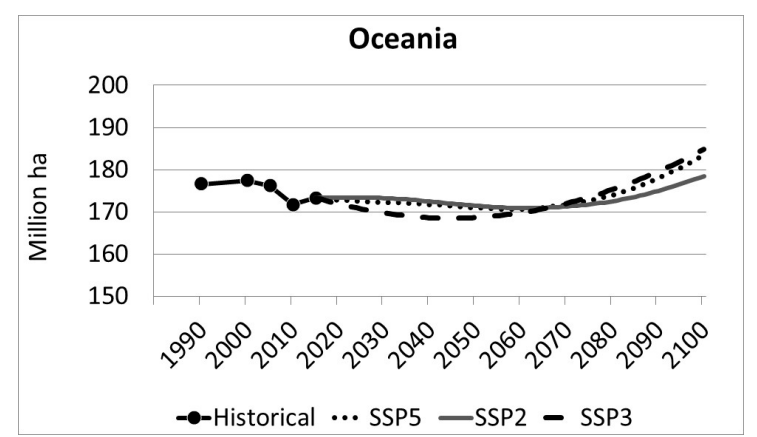

(e)

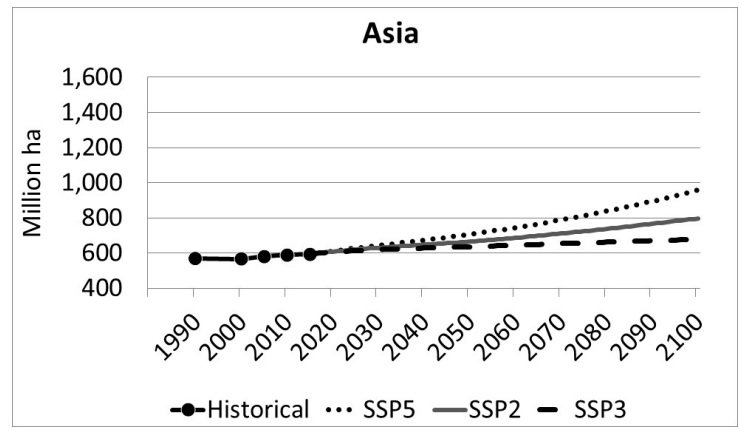

(b)

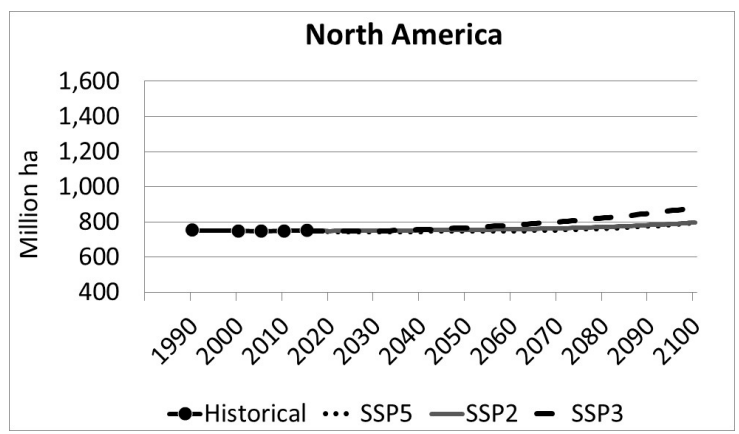

(d)

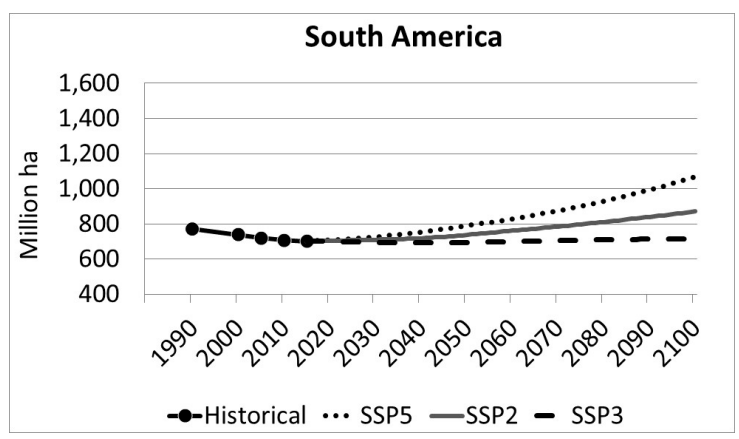

(f)

Figure 2. Projected total forest area (million ha) for major world regions under different shared socioeconomic pathways (SSPs), 2015-2100. Projected explanatory variables driving total forest area projection include per capita income, its squared term, labor per unit forest area, and rural population density. The results represent 48 countries in Africa (a), 46 in Asia (b), 36 in Europe (c), 17 in North America (d), nine in Oceania (e), and 12 in South America (f).

Unlike the trends for other regions, North America and Oceania showed contrasting forest area trends (Figure 2d,e, respectively), where the SSP3 scenario resulted in larger increases in forest area than in SSP5, which are outcomes that are mainly attributable to projected differential rural population 
density trends, which were higher in SSP5, especially in the United States (USA) and Australia (not shown). Accordingly, North America (Figure 2d) showed an increase of 17\% in forest area under SSP3, which is in contrast to smaller (6\%) increases in both SSP5 and SSP2 by 2100, relative to 2015. Similarly, Oceania (Figure 2e) showed a 7\% increase in forest area in SSP3, but smaller increases in SSP5 (6\%) and SSP2 (3\%), respectively by 2100, relative to 2015 .

\section{Discussion}

Our econometric analyses, utilizing more recent and updated data, provided further evidence for the existence of an EKC curve for total forest area. Although not directly comparable, our results align with several past studies that found the evidence for the existence of EKCs for deforestation or forest area, which is contrary to other past studies finding no such support.

Unlike the majority of past EKC studies, which only provided the statistical inferences of their estimated forest area/deforestation EKC models, we used our estimated model to generate projections of forest area in individual countries under varying futures of economic and demographic changes. The evaluation of the projected outlook of forest area at global, regional, and individual country levels under the given socioeconomic futures provided an additional opportunity to validate our estimated model and helped gauge its usefulness for future studies and policy simulations. Consistent with projected explanatory variables and their estimated effects, the total forest area projections generated from our model suggest that the estimated EKC model can be useful in future studies requiring information on how forest area will evolve at aggregate national, regional, or global levels.

A few past studies that employed the EKC model in projecting global forest area used only $\mathrm{Y} / \mathrm{N}$ and $(\mathrm{Y} / \mathrm{N})^{2}$ as drivers, keeping all the other variables constant at the base year level, e.g., as routinely done in the Global Forest Products Model (GFPM) [14,26]. To enable better comparisons with those studies, we generated total forest area projections to 2070 for SSP2 driven only by $\mathrm{Y} / \mathrm{N}$ and (Y/N) ${ }^{2}$, keeping the effect of all the other variables constant at the current level (Figures 3 and 4). These Y/N-only projections could be compared with projections made with the fuller specification. The comparison suggested how not including other important explanatory variables in the projections would produce biased results. For instance, the global projection of forest area in SSP2 was overestimated by $6 \%$ when $\mathrm{R}$ and $\mathrm{L} / \mathrm{A}$ were not used to drive the projections. However, the differences in projections tended to decline and converge over time (Figure 3). Such an upward bias in projection was also true for Africa (4a), North America (4d), and Oceania (4e), which showed up to $24 \%, 11 \%$, and $16 \%$ higher forest area projections in the SSP2 scenario for these three regions, respectively. In contrast, the forest area projections for Asia (4b) and Europe (4c) were lower using the simpler model, by $6 \%$ and 3\%, respectively, when projections were driven only by $\mathrm{Y} / \mathrm{N}$ and $(\mathrm{Y} / \mathrm{N})^{2}$. Finally, the differences for South America between the two projections were smaller, converging toward the end of the projection. Overall, the results obtained by including $\mathrm{R}$ and L/A appear more plausible, given that it more closely captured the most recent trends in forest area in all countries and regions, with less drastic projected changes in future as seen in Figures 3 and $4 \mathrm{a}-\mathrm{f}$.

Next, we compared our projected forest area for SSP2, with projections produced by the 2017 version of GFPM through 2070, which was driven by only $\mathrm{Y} / \mathrm{N}$ and $(\mathrm{Y} / \mathrm{N})^{2}$. The 2017 version of GFPM [27] used in projecting forest area in this study specifies the effect of $\mathrm{Y} / \mathrm{N}$ and $(\mathrm{Y} / \mathrm{N})^{2}$ on forest area annual growth rate as 0.0014 and -0.0898 , respectively. The comparison (not shown) indicated that our projected global forest area was $9 \%$ higher in 2070 , when only $\mathrm{Y} / \mathrm{N}$ and $(\mathrm{Y} / \mathrm{N})^{2}$ were used to drive the projection, but only $4 \%$ higher when $\mathrm{R}$ and $\mathrm{L} / \mathrm{A}$ were additionally used to drive the projection. These projection differences between the two models were up to $1 \%$ for North America, $2 \%$ for Asia, 14\% for South America, and 34\% for Africa, with our model generating higher values than the GFPM projections. 


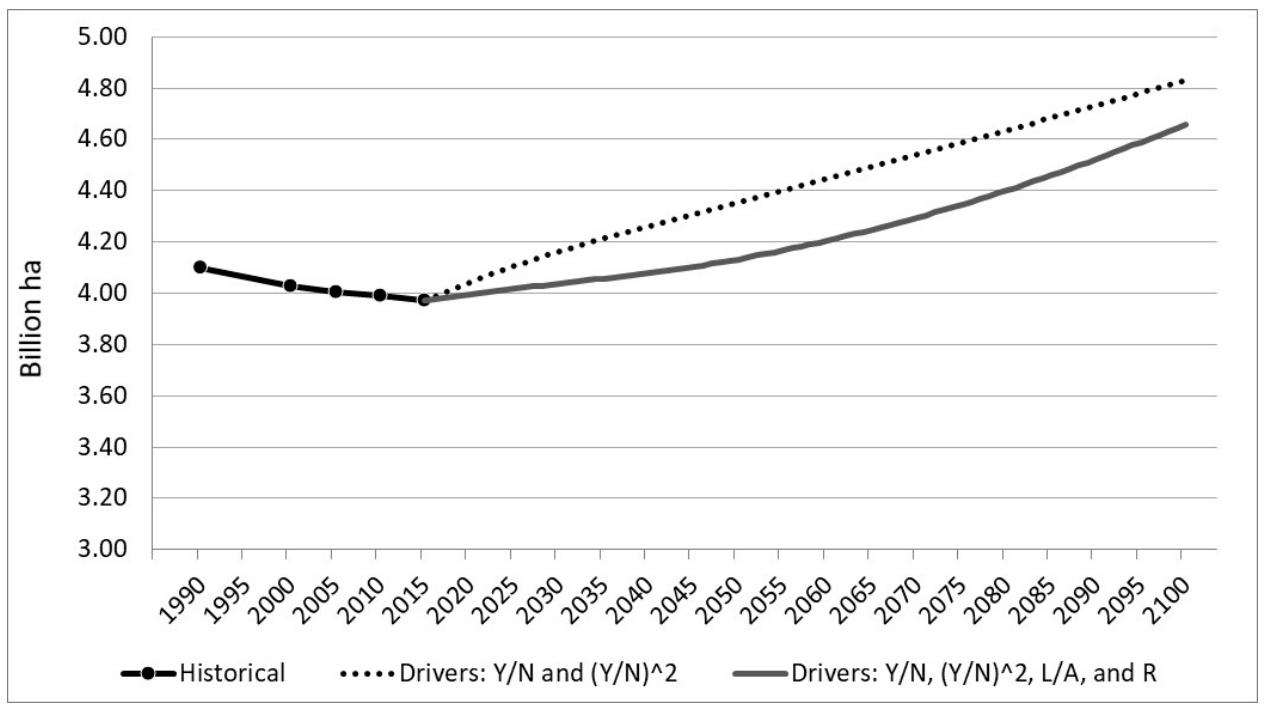

Figure 3. Projected global total forest area (billion ha) under shared socioeconomic pathways two (SSP2), 2015-2100. The dotted line shows forest area driven by only projected per capita income and its squared value, and the solid line shows the projections driven by per capita income, its squared term, rural population density, and labor per unit forest area.

Despite differences in the magnitudes of projected forest areas, our projected trends in global and regional forest area trends are consistent with the future expectation that forest area is on a path toward overall global increases, which is mainly due to advancement in technologies, rural migration to cities, and economic growth. This vision is also in line with perspectives offered by others (e.g., [28]), which have argued that forests are set to recover because of improved forestry methods, the spread of advanced forest governance, and global cooperation and policy.

One key observation based on our projections of total forest area driven only by income per capita and its square values indicates an immediate increase in forest area for all the studied countries and regions, suggesting that the income turning point has already been reached. This increasing trend occurs with any income above $\$ 270$, which is much lower than the values that past studies have indicated (e.g., more than $\$ 800$ ). The seemingly early turning points indicated by our model are expected, since we used all the countries to estimate one single model, rather than estimating separate models for more homogenous country groups. Therefore, our model should be best used to understand the relationship between different explanatory variables and forest area rather than using it to estimate specific turning points.

While our estimated EKC model of forest area captures the effect of important economic and demographic factors and the forest area outlook obtained using the estimated model is consistent with the assumed future changes in economic and demographic variables, caveats should be noted with our model estimates. First, our results might have suffered from the exclusion of other variables in our model, such as policy and institutional factors (e.g., see [7]). Our results do not explicitly consider competition for land between various uses, which is mainly determined by the economics of each land use (e.g., land rent). For instance, increasingly richer populations with changing diet preferences (e.g., more meat consumption) in the future may lead to increased demand for land for food and feed production, leading to either deforestation or no land area available for afforestation/reforestation (e.g., see [29]). Similarly, increasing future demand for wood energy may lead to increased wood prices, which may drive up forestland rents (the profitability of forestland) and thereby limit forestland conversion to other uses, (e.g., see [30]). Alternatively, higher bioenergy prices may lead to the conversion of natural forests or timber-oriented plantations to short rotation woody or herbaceous bioenergy crops (e.g., see [31]). 


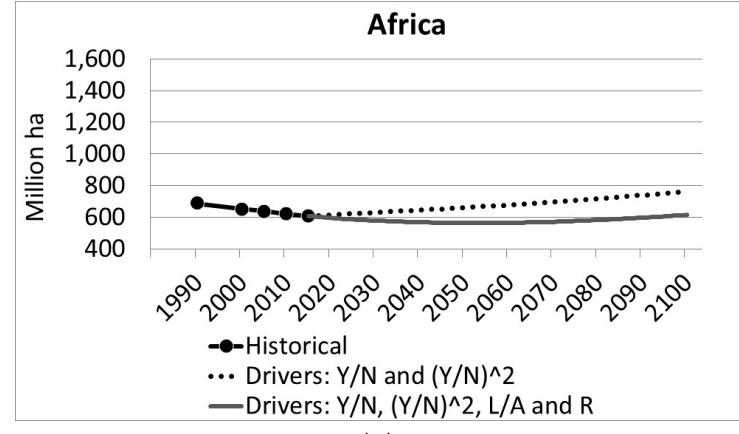

(a)

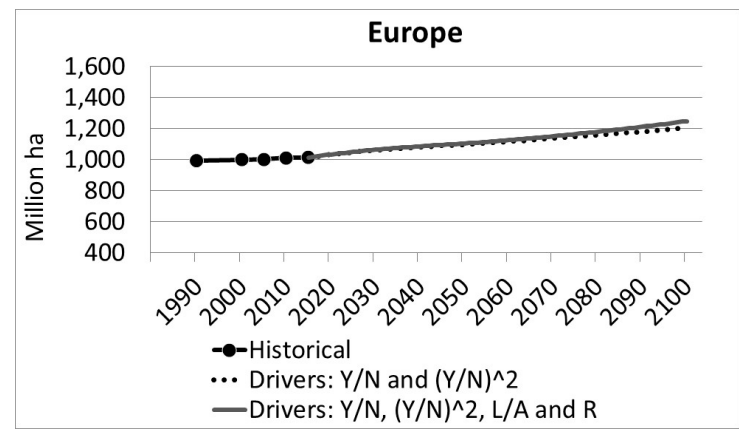

(c)

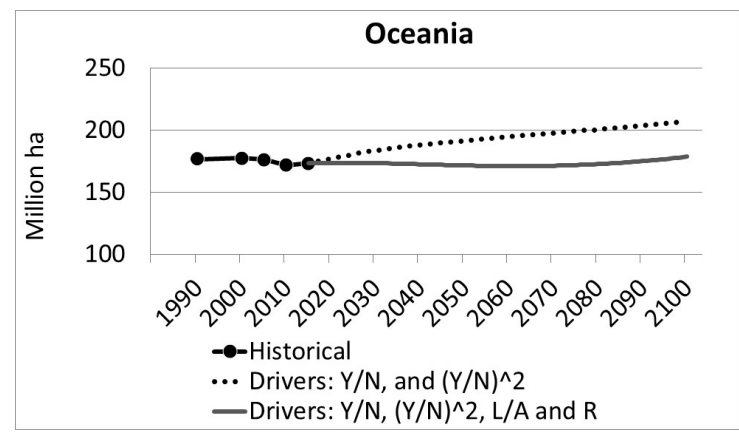

(e)

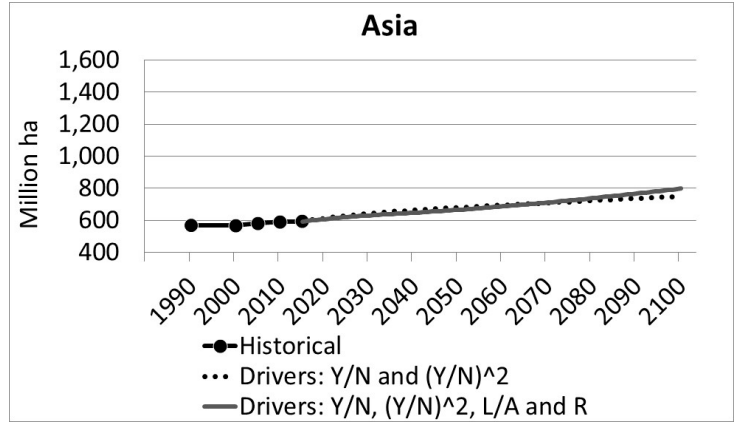

(b)

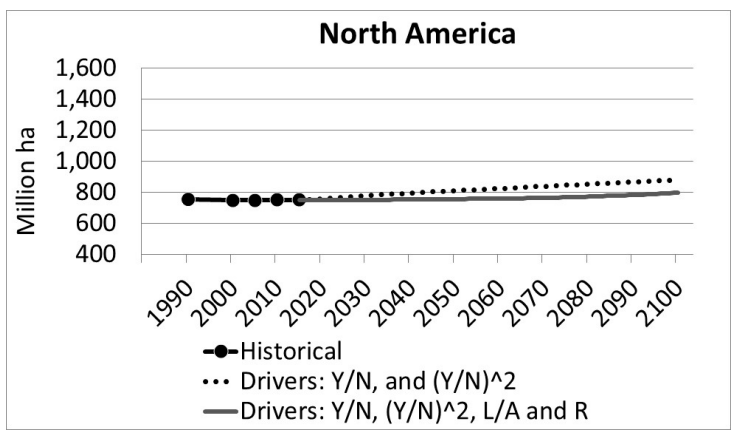

(d)

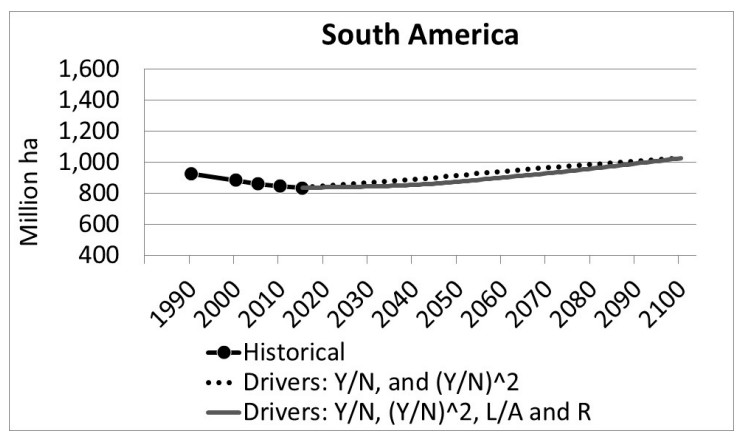

(f)

Figure 4. Projected total forest area (million ha) for major world regions under shared socioeconomic pathways two (SSP2), 2015-2100. The dotted line shows forest area projections driven by only per capita income and its squared value, and the solid line shows the projections driven by per capita income, its squared term, rural population density, and labor per unit forest area. The results represent 48 countries in Africa (a), 46 in Asia (b), 36 in Europe (c), 17 in North America (d), nine in Oceania (e), and 12 in South America (f).

We also acknowledge that forest area EKC modeling, without distinguishing between natural and planted forests, may have contributed to some uncertainties. Total forest area is the sum of natural forests and planted forests, and in reality, natural forests and planted forests are not necessarily driven by the same microeconomic, social, and policy factors [6]. For instance, while the expansion (or contraction) of planted forests is driven mainly by economics [32], natural forest area is more directly affected by demands for various ecosystem services and regional economic development goals. Future research could provide an improved understanding of the relationship between income and planted and natural forest areas.

The lack of distinction between natural and planted forests in our EKC models suggests that the projected future changes in total forest area reported in this study may not necessarily imply a proportionate increase in climate change mitigation benefit. The recent data indicate rising trends for 
planted forest area and declining trends for natural forest area [20]. If such trends are to continue into the future, it is important to emphasize that compensating planted forest carbon gains will lag natural forest deforestation carbon losses while young planted trees grow, which is a process than can take several decades to play out. The long-term climate change mitigation benefits of increasing forest area also depend on the actual impacts of climate change on forest growth, which could be either positive, for example, due to increasing $\mathrm{CO}_{2}$ fertilization, growing season lengthening, and precipitation increases, or negative, due to greater water stresses brought about by higher temperatures.

\section{Conclusions}

Overall, three key results from our study contribute to an enhanced understanding of the relationships between total forest area, income per capita, rural population density, and labor per unit forest area analyzed under the EKC framework. First, we provided an updated test of the EKC for total forest area. Our results provide further support for the existence of an EKC curve for total forest area, further indicating the very high explanatory powers of rural population density and labor per unit forest area. Second, our study provided an outlook for total forest area for 168 countries under varying projected futures of socioeconomic changes. Aside from revealing the likely divergent trends in forest area across SSPs, the results indicate how forest area is likely to increase under most projected futures. Third, our forest area projections revealed how the inclusion of additional explanatory variables in an EKC model of forests provides a fuller picture of global forest area trends, compared to a model that limits differences across models to be solely captured by income per capita.

Supplementary Materials: The following are available online at http://www.mdpi.com/1999-4907/10/5/387/s1, Table S1: Projected total forest area (million ha) and percentage changes by 2100, compared to 2015 levels under different shared socioeconomic pathways (SSPs), Figure S1: Projected average per capita gross domestic product for major world regions under different shared socioeconomic pathways (SSPs), Figure S2: Projected rural population density (persons $\mathrm{ha}^{-1}$ ) for major world regions under different shared socioeconomic pathways (SSPs), 2015-2100, Figure S3: Projected average labor per unit forest area (persons ha ${ }^{-1}$ ) for major world regions under different shared socioeconomic pathways (SSPs), 2015-2100.

Author Contributions: Conceptualization, J.P., and P.N.; Methodology, P.N., J.K., and J.P.; Software, P.N., and J.K.; Validation, P.N., J.K, J.P., and F.C.; Formal Analysis, P.N., and J.K.; Investigation, P.N., J.K, J.P. and F.C.; Data Curation, P.N., and J.K.; Writing - Original Draft Preparation, P.N..; Writing - J.K., J.P., F.C., and P.N.; Visualization, P.N.; Project Administration, J.P.; Funding Acquisition, J.P.

Funding: This research was funded by the USDA Forest Service, Resource Planning Act (RPA) Assessment program, grant number 14-JV-11330143-101.

Acknowledgments: The authors would like to thank Elias Hurmekoski and Arttu Malkamäki for their helpful comments on the earlier version of the manuscript. Korhonen thanks the Academy of Finland for financial support (307480). Authors also thank two anonymous reviewers whose comments helped further improve this paper.

Conflicts of Interest: The authors declare no conflict of interest. The funders had no role in the design of the study; in the collection, analyses, or interpretation of data; in the writing of the manuscript, or in the decision to publish the results.

\section{References}

1. Kuznets, S. Economic growth and income inequality. Am. Econ. Rev. 1955, 45, 1-28.

2. Grossman, G.M.; Krueger, A. Environmental Impacts of a North American Free Trade Agreement; NBER Working Paper No. 3914; MIT Press: Cambridge, MA, USA, 1991.

3. Shafik, N.; Bandyopadhyay, S. Economic Growth and Environmental Quality: Time Series and Cross-Country Evidence; Background paper for the World Development Report; The World Bank: Washington, DC, USA, 1992; Available online: http://documents.worldbank.org/curated/en/833431468739515725/pdf/multi-page.pdf (accessed on 11 October 2018).

4. Dinda, S. Environmental Kuznets curve hypothesis: a survey. Ecol. Econ. 2004, 49, 431-455. [CrossRef]

5. Panayotou, T. Empirical Tests and Policy Analysis of Environmental Degradation at Different Stages of Economic Development; Working Paper WP238, Technology and Employment Programme; International Labor Office: Geneva, France, 1993. 
6. Cropper, M.; Griffiths, C. The interaction of population growth and environmental quality. Am. Econ. Rev. 1994, 84, 250-254.

7. Bhattarai, M.; Hammig, M. Institutions and the environmental Kuznets curve for deforestation: A cross-country analysis for Latin America, Africa and Asia. World Dev. 2001, 29, 995-1010. [CrossRef]

8. Joshi, P.; Beck, K. Environmental Kuznets curve for deforestation: Evidence using GMM estimation for OECD and non-OECD regions. iForest 2017, 10, 196-203. [CrossRef]

9. Cuaresma, J.C.; Danylo, O.; Fritz, S.; McCallum, I.; Obersteiner, M.; See, L.; Walsh, B. Economic development and forest cover: Evidence from satellite data. Sci. Rep. 2017, 7, 40678. [CrossRef]

10. Meyer, A.L.; Van Kooten, G.C.; Wang, S. Institutional, social and economic roots of deforestation: A cross-country comparison. Int. For. Rev. 2003, 5, 29-37. [CrossRef]

11. Barbier, E.B. Explaining agricultural land expansion and deforestation in developing countries. Am. J. Agric. Econ. 2004, 86, 1347-1353. [CrossRef]

12. Ferreira, S. Deforestation, property rights, and international trade. Land Econ. 2004, 80, 174-193. [CrossRef]

13. Culas, R.J. Deforestation and the environmental Kuznets curve: An institutional perspective. Ecol. Econ. 2007, 61, 429-437. [CrossRef]

14. Turner, J.A.; Buongiorno, J.; Zhu, S. An economic model of international wood supply, forest stock and forest area change. Scand. J. For. Res. 2006, 21, 73-86. [CrossRef]

15. Nguyen-Van, P.; Azomahou, T. Nonlinearities and heterogeneity in environmental quality: An empirical analysis of deforestation. J. Dev. Econ. 2007, 84, 291-309. [CrossRef]

16. FAO. FRA 2015 Terms and Definition. Forest Resource Assessment Working Paper 180. Available online: http://www.fao.org/docrep/017/ap862e/ap862e00.pdf (accessed on 6 April 2018).

17. Buongiorno, J. Global modelling to predict timber production and prices: The GFPM approach. Forestry 2015, 88, 291-303. [CrossRef]

18. Antweiler, W.; Copeland, B.R.; Taylor, M.S. Is free trade good for the environment? Am. Econ. Rev. 2001, 91, 877-908. [CrossRef]

19. Cole, M.A.; Elliott, R.J.R. Determining the trade environment composition effect: The role of capital, labor and environmental regulations. J. Environ. Econ. Manage. 2003, 46, 363-383. [CrossRef]

20. FAO. Global Forest Resource Assessment 2015: Desk Reference. Available online: http://www.fao.org/3/ai4808e.pdf (accessed on 27 March 2018).

21. World Bank. World Bank Open Data. 2018. Available online: https://data.worldbank.org/ (accessed on 12 March 2018).

22. Feenstra, R.C.; Inklaar, R.; Timmer, M.P. The next generation of the Penn World table. Am. Econ. Rev. 2015, 105, 3150-3182. [CrossRef]

23. O’Neill, B.C.; Kriegler, E.; Ebi, K.L.; Kemp-Benedict, E.; Riahi, K.; Rothman, D.S.; van Ruijven, B.J.; van Vuuren, D.P.; Birkmann, J.; Kok, K.; et al. The roads ahead: Narratives for shared socioeconomic pathways describing world futures in the 21st century. Glob. Environ. Change 2017, 42, 169-180. [CrossRef]

24. IIASA. SSP Database, International Institute for Applied Systems Analysis, Vienna, Austria. Available online: https://ntcat.iiasa.ac.at/SspDb (accessed on 3 June 2018).

25. Jiang, L.; O'Neill, B.C. Global urbanization projections for the Shared Socioeconomic Pathways. Glob. Environ. Chang. 2017, 42, 193-199. [CrossRef]

26. Buongiorno, J. Income and time dependence of forest product demand elasticities and implications for forecasting. Silva Fenn. 2015, 49, 1395. [CrossRef]

27. Buongiorno, J.; Zhu, S. Using the Global Forest Products Model (GFPM version 2016 with BPMPD); Staff Paper Series \# 85; Department of Forest and Wildlife Ecology, University of Wisconsin: Wisconsin, MA, USA, 2016.

28. Blaser, J.; Gregerson, H. Forests in the next 300 years. Unasylva 2013, 64, 61-73.

29. Schneider, U.A.; Havlik, P.; Schmid, E.; Valin, H.; Mosnier, A.; Obersteiner, M.; Böttcher, H.; Balkovič, J.; Skalský, R.; Sauer, T.; et al. Impacts of population growth, economic development, and technical change on global food production and consumption. Agric. Syst. 2011, 104, 204-215. [CrossRef]

30. Nepal, P.; Abt, K.L.; Skog, K.E.; Prestemon, J.P.; Abt, R.C. Projected market competition for wood biomass between traditional products and energy: A simulated interaction of us regional, national, and global forest product markets. For. Sci. 2019, 65, 14-26. [CrossRef] 
31. Latta, G.S.; Baker, J.S.; Beach, R.H.; Rose, S.K.; McCarl, B.A. A multi-sector intertemporal optimization approach to assess the GHG implications of U.S. forest and agricultural biomass electricity expansion. J. For. Econ. 2013, 19, 361-383. [CrossRef]

32. Cubbage, F.; Donagh, P.M.; Balmelli, G.; Olmos, V.M.; Bussoni, A.; Rubilar, R.; Torre, R.; Lord, R.; Huang, J.; Hoeflich, V.A.; et al. Global timber investments and trends, 2005-2011. N. Z. J. For. Sci. 2014, 44, S7. [CrossRef]

(C) 2019 by the authors. Licensee MDPI, Basel, Switzerland. This article is an open access article distributed under the terms and conditions of the Creative Commons Attribution (CC BY) license (http://creativecommons.org/licenses/by/4.0/). 